\title{
Decomposing socioeconomic inequality in poor mental health among Iranian adult population: results from the PERSIAN cohort study
}

Farid Najafi ${ }^{1}$, Yahya Pasdar ${ }^{2}$, Behzad Karami Matin ${ }^{1}$, Satar Rezaei ${ }^{1}$, Ali Kazemi Karyani ${ }^{1}$, Shahin Soltani ${ }^{1}$, Moslem Soofi ${ }^{3}$, Shahab Rezaeian', Alireza Zangeneh ${ }^{3}$, Mehdi Moradinazar ${ }^{1}$, Behrooz Hamzeh', Zahra Jorjoran Shushtari ${ }^{4}$, Mansour sajjadipour ${ }^{5}$, Saeid Eslami ${ }^{6}$, Maryam khosrojerdi ${ }^{7}$, Sahar Shabestari ${ }^{8}$, Amir Houshang Mehrparvar ${ }^{9}$, Zahra Kashi ${ }^{10}$, Azim Nejatizadeh ${ }^{11}$, Mohammadreza Naghipour ${ }^{12}$, Shahrokh Sadeghi Boogar ${ }^{13}$, Ali Fakhari ${ }^{14}$, Bahman Cheraghian ${ }^{15}$, Haydeh Heidari ${ }^{16}$, Parviz Molavi ${ }^{17}$, Mohammad Hajizadeh ${ }^{18}$ and Yahya Salimi ${ }^{19^{*}}$ (D)

\section{Abstract}

Background: Socioeconomic inequality in mental health in Iran is poorly understood. This study aimed to assess socioeconomic inequality in poor mental health among Iranian adults.

Methods: The study used the baseline data of PERSIAN cohort study including 131,813 participants from 17 geographically distinct areas of Iran. The Erreygers Concentration index (E) was used to quantify the socioeconomic inequalities in poor mental health. Moreover, we decomposed the $E$ to identify factors contributing to the observed socioeconomic inequality in poor mental health in Iran.

Results: The estimated E for poor mental health was - 0.012 (95\% Cl: $-0.0144,-0.0089)$, indicating slightly higher concentration of mental health problem among socioeconomically disadvantaged adults in Iran. Socioeconomic inequality in poor mental health was mainly explained by gender (19.93\%) and age (12.70\%). Region, SES itself, and physical activity were other important factors that contributed to the concentration of poor mental health among adults with low socioeconomic status.

Conclusion: There exists nearly equitable distribution in poor mental health among Iranian adults, but with important variations by gender, SES, and geography. These results suggested that interventional programs in Iran should focus on should focus more on socioeconomically disadvantaged people as a whole, with particular attention to the needs of women and those living in more socially disadvantaged regions.

Keywords: Mental health, Socioeconomic inequality, Concentration index, Decomposition

\footnotetext{
* Correspondence: salimiyahya@yahoo.com

${ }^{19}$ Social Development and Health Promotion Research Center, Health Institute, Kermanshah University of Medical Sciences, Kermanshah, Iran Full list of author information is available at the end of the article
}

(c) The Author(s). 2020, corrected publication 2022. Open Access This article is licensed under a Creative Commons Attribution 4.0 International License, which permits use, sharing, adaptation, distribution and reproduction in any medium or format, as long as you give appropriate credit to the original author(s) and the source, provide a link to the Creative Commons licence, and indicate if changes were made. The images or other third party material in this article are included in the article's Creative Commons licence, unless indicated otherwise in a credit line to the material. If material is not included in the article's Creative Commons licence and your intended use is not permitted by statutory regulation or exceeds the permitted use, you will need to obtain permission directly from the copyright holder. To view a copy of this licence, visit http://creativecommons.org/licenses/by/4.0/ The Creative Commons Public Domain Dedication waiver (http://creativecommons.org/publicdomain/zero/1.0/) applies to the data made available in this article, unless otherwise stated in a credit line to the data. 


\section{Background}

Mental health disorders are one of the global leading causes of morbidity and mortality influence on several aspects of life including quality of life, physical well-being, social cohesion, and productivity [1]. One systematic review by Steel et al. reported that the global prevalence of most common mental health disorders including anxiety and substance use disorders ranged between 16 and 19\% [2]. Based on the 2017 Global Burden of Disease report, mental health disorders are responsible for 14\% of age-standardized years lived with disabilities in the last three decades [3]. The prevalence of the mental health disorders in Iran has been shown an increase from $21 \%$ in 1999 to $24 \%$ in 2011 [4].

It is increasingly known that poor mental health has been disproportionately distributed across socioeconomic groups in a population $[5,6]$. Several studies indicated that the distribution of good mental health is heavily skewed towards the higher socioeconomic groups [5, 7, 8]. A systematic review of literature by Lund et al.(2010) showed that there is a convincing evidence of association between poverty and poor mental health [5].

As many structural, social, and environmental factors have attributed to the socioeconomic inequality in poor mental health, underlying mechanisms of association between SES and poor mental health seems to be complex [9]. The poor mental health can be one of the determinants and also consequences of the socioeconomic inequality [9]. However, evidence on socioeconomic inequality in mental health from low- and middle-income countries including Iran is scarce. A context-based study for enhancing the current knowledge of socioeconomic inequalities in poor mental health is greatly warranted. Given the preventable nature of the socioeconomic inequality, providing related information on the poor mental health distribution would be useful for understanding the burden of the problem, guiding policy makers and developing practical preventive interventions. Thus, the aim of present study is to quantify the extent of socioeconomic-related inequality in poor mental health among Iranian adults and to understand determinants of socioeconomic inequality in poor mental health.

\section{Methods}

Data

We used the baseline data of Prospective Epidemiological Research in IrAN (PERSIAN) that included the data on 131,813 Iranians aged 35 years and older, from 14 provinces of Iran, in 17 geographically distinct cohort sites. These cohort sites include Kermanshah, Guilan, Fasa, Tabriz, Kharameh, Mazandaran, Zahedan, Yazd, Rafsanjan, Ahvaz, Shahrekurd, Bandar Abbas, Uromieh,
Ardabil, Sabzevar, Mashhad, Yasuj, Kavar. As data of Fasa, Kavar and Kharameh sites came from Fars province, and Sabzevar and Mashahd from Razavi Khorasan province; therefore, the data in from the same sites of these provinces were merged. Because the process of recruitment has not been completed in time of data analysis, the Yasuj cohort was excluded from this study. In each site, men and women aged 35-70 years, residing within the PERSIAN Cohort sites are invited to participate in the study. Other inclusion criteria included: being of Iranian descent and living in the designated areas for at least 9 months of the year. Anyone with physical or psychological disabilities, that unable to complete the enrollment process was excluded from the study. This yielded a total final sample size of 130,078 adults aged 35-70 years old. More details about PERSIAN Cohort study were presented elsewhere [10, 11]. The characteristics of included cohort sites are described in Appendix 1.

\section{Measures}

Poor mental health was defined as a binary variable based on self-report of related treatments for at least 3 month during the past year which recorded by a general physician: Citalopram, Escitalopram, Sertraline, Paroxetine, Clozapine, Quetiapine, Risperidone, Haloperidol, Chlorpromazine, Olanzapine, Aripiprazole, Fluphenazine, Perphenazine, Trifluoperazine, Fluoxetine, Valproate sodium, Lamotrigine, Alprazolam, Clonazepam, Lorazepam, Flurazepam, Buspirone, Zolpidem, Lithium, Carbamazepine, Tranylcypromine, Venlafaxine, Fluvoxamine, Trazodone, Duloxetine, Oxcarbazepine, Doxepin, Maprotiline, Trimipramine, Clomipramine, Nortriptyline, Desipramine, Amitriptyline. Although, we had access to self-reported past history of depression and any other mental health problems, diagnosed by physician, we did not include such variables in our definition as we aimed to investigate about inequality in mental health problems under the treatment. Using principal component analysis, the socioeconomic status (SES) variable was constructed by assessing ownership of household assets, and educational level of individuals. Twenty six items i.e. having car, motorcycle, bicycle, refrigerator, freezer, radio, stove, vacuum machine, personal computer, CD/DVD player, sewing machine, cooler, washing mashing, microwave, central heating, having kitchen, bathroom, use of natural gas for cooking, per capita house area per capita rooms, access to piped drinking water, electricity, telephone, internet, sewage network, and educational level were used in the construction of SES indicator. The SES index was grouped into five quintiles, where the 1st quintile represents the poorest group and the 5 th quintile represents the richest one. Dummy variables for the age group, marital status, 
body mass index (BMI), smoking status, SES quantiles, and 14 sites of PERSIAN cohort were included in the analysis as determinants of poor mental health.

\section{Statistical analysis}

Measuring and decomposing poor mental health inequality

The concentration index $(C)$ approach $[12,13]$ was used to measure socioeconomic inequality in poor-mental health outcome. The $\mathrm{C}$ is based on the Concentration curve which plots cumulative proportion of population ranked in ascending order of SES in $\mathrm{x}$-axis and cumulative proportion of poor mental health in $\mathrm{y}$-axis. The $\mathrm{C}$ is defined as twice the area between the concentration curve and line of perfect equality (i.e., 45-degree line). Formally, the $\mathrm{C}$ can be calculated as:

$$
C=\frac{2}{\mu} \operatorname{cov}\left(Y_{i}, R_{i}\right)
$$

Where $\mu$ is the mean of poor mental health disorder, $y_{i}$ is the mental health disorder status of the $i$ th individual and $R_{i}$ is the fractional rank that individual $i$ represents in total population ranked by SES. The $C$ is bounded between the values of -1 and +1 . Negative values imply that poor mental health is more concentrated among the poor people and positive values imply that poor mental health is more concentrated among rich people. If the $\mathrm{C}$ is equal to zero it suggests that there is no socioeconomic inequality in mental health disorder. If health outcome variable in bounded, the estimated value of the $C$ is not between -1 and +1 . Thus, we used Erreygers Concentration index (E) [14] to account for the bounded nature of binary health outcome variables. The formula for the $\mathrm{E}$ is as follows:

$$
E=\frac{4 \mu}{y^{\max }-y^{\min }} C .
$$

Where $y^{\max }$ and $y^{\max }$ are the minimum and maximum value of the bounded variable (i.e., one and zero for binary variable).

The $\mathrm{E}$ can be decomposed to identify the contributions of relevant factors to socioeconomic inequality in mental health disorder. Assuming a linear relationship between mental health disorder and a set of $k$ explanatory variables $x$, the $\mathrm{E}$ can be expressed as a weighted sum of the partial Concentration index for the explanatory factors of socioeconomic inequality, $C_{k}$ as:

$$
E=4\left[\sum_{k}\left(\beta_{k} \bar{x}_{k}\right) C_{k}+G C_{\varepsilon}\right]
$$

Where $\bar{x}_{k}$ is the means of explanatory variables, $\beta_{k}$ is the coefficient on explanatory variable $k$ obtained from the generalized linear model of the binomial family with a logit link function linking mental health disorder to the explanatory variables, and $G C_{\varepsilon}$ is the generalized $C$ for the error term. If the value of the contribution of variable $k$ is $\theta$, for both positive (negative) signs, then the inequality in poor mental health would decrease (increase) by $\theta$ percent if the variable was to become equally distributed across the socioeconomic groups. Normal-based 95\% bootstrap confidence intervals with 1000 replication were calculated. The level of significance (alpha level) in all analyses was set at 0.05 . Records with missing data were excluded because the amount of missing data was small less than $1 \%$ and assumed to be missing at random. Statistical analysis procedures were conducted using STATA 11 [15] and the Es were calculated using Stata's "conindex" command [16].

\section{Results \\ Descriptive results}

As shown in Table 1, from total of 131,813 participants, nearly $45 \%$ of the study sample were male; most participants were $35-40$ years $(20.83 \%)$ and belonged to the overweight category $(40.76 \%)$. The majority of participants were married (90.94\%), non-smoker (86\%) and non-alcohol user $(90.96 \%) .11 \%$ of the participants were water-pipe user.

Age-adjusted proportion of poor mental health was 6.23\% (95\% Confidence Interval [CI]: 6.09, 6.36). The proportion of poor mental health among the females $(8.14 \%)$ was higher compared to the males $(4.29 \%)$. The cohort sites of Sistan and Balouchestan (11.77), and Razavi Khorasan (1.52) had higher and lower proportion of poor mental health among PERSIAN cohort sites (see Fig. 1a).

\section{Socioeconomic inequality in poor mental health}

Table 2 and Fig. 1b show the Erreygers concentration indices $\left(C_{k}\right)$ for poor mental health for all separate sites of the PERSIAN cohort. The result shows that the overall E was - 0.012 (95\% CI: - 0.0144 to - 0.0089), indicating the slightly higher concentration of poor mental health among less-advantaged people $(P<0.001)$. The values of $C_{k}$ were not statistically significant for the Fars, Kermanshah, and Khuzestan sites. All the $C_{k}$ values had negative signs, except for the Mazandaran site $\left(C_{k}=\right.$ 0.0392, $P<0.001)$.

\section{Determinants of socioeconomic inequality in poor mental health}

The results of the decomposition analysis are presented in Tables 3. The table presents elasticity, coefficient estimates, the $C_{k}$, absolute contributions, and percentage contribution for each explanatory factor to poor mental health. A positive coefficient indicates that the participants 
Table 1 Characteristics of study participants by mental health disorders $(n=130,078)$

\begin{tabular}{|c|c|c|c|}
\hline & All participants & Poor mental health & Good mental health \\
\hline & N (\%) & N (\%) & N (\%) \\
\hline \multicolumn{4}{|l|}{ Age groups } \\
\hline $35-40$ & 27,094 (20.83) & $1094(4.04)$ & $26,000(95.96)$ \\
\hline $40-45$ & 24,195 (18.60) & $1189(4.91)$ & $23,006(95.09)$ \\
\hline $45-50$ & $22,489(17.29)$ & $1468(6.53)$ & $21,021(93.47)$ \\
\hline $50-55$ & $20,160(15.50)$ & $1601(7.94)$ & 18,559 (92.06) \\
\hline $55-60$ & $17,442(13.41)$ & $1431(8.20)$ & $16,011(91.80)$ \\
\hline $60-65$ & $12,154(9.34)$ & $984(8.10)$ & $11,170(91.90)$ \\
\hline $65>$ & $6544(5.03)$ & $581(8.88)$ & $5963(91.12)$ \\
\hline \multicolumn{4}{|l|}{ Gender } \\
\hline Male & $58,251(44.78)$ & $2499(4.29)$ & $55,752(95.71)$ \\
\hline Female & $71,827(55.22)$ & $5849(8.14)$ & $65,978(91.86)$ \\
\hline \multicolumn{4}{|l|}{ Marital status } \\
\hline Single & $2953(2.27)$ & $176(5.96)$ & $2777(94.04)$ \\
\hline Married & $118,290(90.94)$ & $7239(6.12)$ & $111,051(93.88)$ \\
\hline Divorced & $1447(1.11)$ & $125(8.64)$ & $1322(91.36)$ \\
\hline widowed & 7305 (5.62) & $802(10.98)$ & $6503(89.02)$ \\
\hline other & $83(0.06)$ & $6(7.23)$ & $77(92.77)$ \\
\hline \multicolumn{4}{|l|}{ Water-pipe use } \\
\hline No & 114,594 (88.92) & $7395(6.45)$ & 107,199 (93.55) \\
\hline Yes & $14,284(11.08)$ & $949(6.47)$ & 13,335 (93.53) \\
\hline \multicolumn{4}{|l|}{ Alcohol Use } \\
\hline No & 117,225 (90.96) & 7737 (6.60) & $109,488(93.40)$ \\
\hline Yes & $11,652(9.04)$ & $606(5.20)$ & $11.046(94.80)$ \\
\hline \multicolumn{4}{|l|}{ Drug use } \\
\hline No & $113,514(88.08)$ & $7143(6.29)$ & $106,371(93.71)$ \\
\hline Yes & $15.363(11.92)$ & $1201(7.82)$ & 14,162 (92.18) \\
\hline \multicolumn{4}{|l|}{ Smoking status } \\
\hline Non-smoker & $91,174(77.81)$ & $6636(7.28)$ & $84,538(92.72)$ \\
\hline Ex-smoker & $9166(7.82)$ & $589(6.43)$ & $8577(93.57)$ \\
\hline Smoker & $16,831(14.36)$ & $1112(6.61)$ & 15,719 (93.39) \\
\hline \multicolumn{4}{|c|}{ Physical activity (Daily METs) } \\
\hline Inactive (24-36.5) & $44,075(33.89)$ & $3673(8.33)$ & $40,402(91.67)$ \\
\hline Middle (36.6-44.9) & $60,585(46.59)$ & $3.699(6.11)$ & $56,886(93.89)$ \\
\hline Active $(\geq 45)$ & $25,388(19.52)$ & $975(3.84)$ & $24,413(96.16)$ \\
\hline \multicolumn{4}{|l|}{ BMI } \\
\hline Underweight & $2558(1.98)$ & $155(6.06)$ & $2403(93.94)$ \\
\hline Normal & $34,808(26.90)$ & $1933(5.55)$ & $32,875(94.45)$ \\
\hline Overweight & $52,731(40.76)$ & $3291(6.24)$ & $49,440(93.76)$ \\
\hline Obese & $39,279(30.36)$ & $2938(7.48)$ & $36,341(92.52)$ \\
\hline \multicolumn{4}{|l|}{ Socioeconomic status } \\
\hline 1st SES quintile (Poorest) & 26,095 (20.06) & $1813(6.95)$ & $24,282(93.05)$ \\
\hline 2nd SES quintile & $26,035(20.01)$ & $1777(6.83)$ & $24,258(93.17)$ \\
\hline 3rd SES quintile & 26,007 (19.99) & $1766(6.79)$ & $24,241(93.21)$ \\
\hline
\end{tabular}


Table 1 Characteristics of study participants by mental health disorders $(n=130,078)$ (Continued)

\begin{tabular}{|c|c|c|c|}
\hline & All participants & Poor mental health & Good mental health \\
\hline & N (\%) & N (\%) & N (\%) \\
\hline 4th SES quintile & $25,940(19.94)$ & $1566(6.04)$ & $24,374(93.96)$ \\
\hline 5th SES quintile (Richest) & 26,001 (19.99) & $1426(5.48)$ & $24,575(94.52)$ \\
\hline \multicolumn{4}{|l|}{ Region of cohort (province) } \\
\hline Fars (FA) & $22,767(17.50)$ & $1471(6.46)$ & $21,296(93.54)$ \\
\hline Kermanshah (KSH) & $10,036(7.72)$ & $257(2.56)$ & $9779(97.44)$ \\
\hline Guilan (GU) & $10,433(8.02)$ & $903(8.66)$ & $9530(91.34)$ \\
\hline East Azerbaijan (EA) & $14,775(11.36)$ & $1072(7.26)$ & $13,703(92.74)$ \\
\hline Mazandaran (MA) & $10,103(7.77)$ & $964(9.54)$ & $9139(90.46)$ \\
\hline Sistan and Balouchestan (SB) & 8199 (6.30) & $965(11.77)$ & $7234(88.23)$ \\
\hline Yazd (YA) & $9723(7.47)$ & $577(5.93)$ & $9146(94.07)$ \\
\hline Kerman (KE) & 9788 (7.52) & 857 (8.76) & 8931 (91.24) \\
\hline Khuzestan (KH) & $9139(7.03)$ & $148(1.62)$ & 8991 (98.38) \\
\hline Chaharmahal and Bakhtiari (CB) & $6730(5.17)$ & $450(6.69)$ & $6280(93.31)$ \\
\hline Hormozgan (HO) & $3557(2.73)$ & $110(3.09)$ & 3447 (96.91) \\
\hline West Azerbaijan (WA) & $3660(2.81)$ & $157(4.29)$ & 3503 (95.71) \\
\hline Ardabil (AR) & $8214(6.31)$ & $372(4.53)$ & $7842(95.47)$ \\
\hline Razavi Khorasan (RK) & $2954(2.27)$ & 45 (1.52) & 2909 (98.48) \\
\hline
\end{tabular}

with the explanatory variable were more likely to have poor mental health status and vice-versa.

The $C_{k}$ was estimated for each explanatory factor of poor mental health. A negative (positive) sign shows that the explanatory variable has a pro-poor (pro-rich) distribution. Variables such as age categories of 50-55, 55$60,60-65$, and $>65$, marital status categories of divorced, widows, and others, drug users, non-smokers, physically active and living in Cohort sites of Kermanshah, Guilan, East Azerbaijan, Khouzestan, Hormozgan, and West Azerbaijan had negative concentration indices, indicating that these predictors were concentrated among the pro-poor population. A negative (positive) absolute contribution of predictors means that socioeconomic inequality in poor mental health would, the value of $C_{k}$, increase (decrease) if that predictor would be equally distributed across the SES distribution. All predictors included in the decomposition analysis explained $27.1 \%$ of overall inequality in poor mental health.

Gender explains the most of observed inequality in poor mental health . Figure 2 illustrates the results of decomposition analysis by gender. The contribution to $C_{k}$ a)

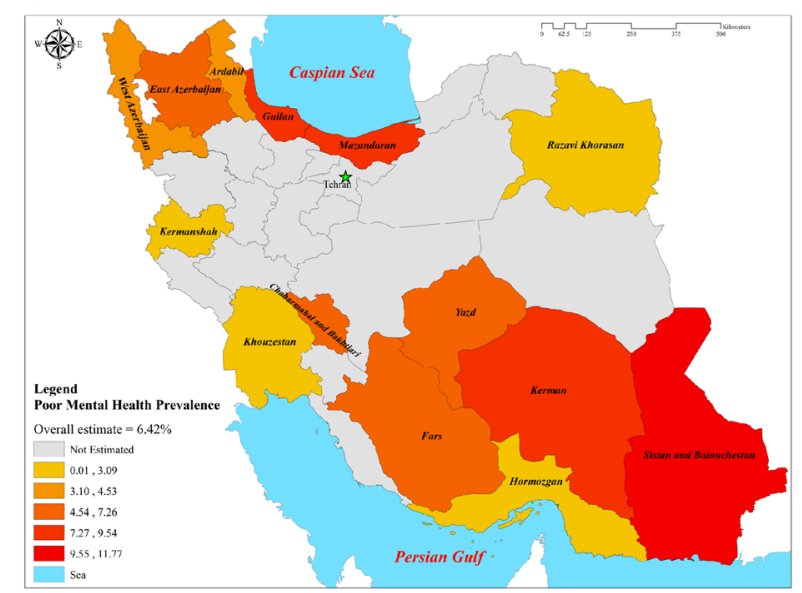

b)

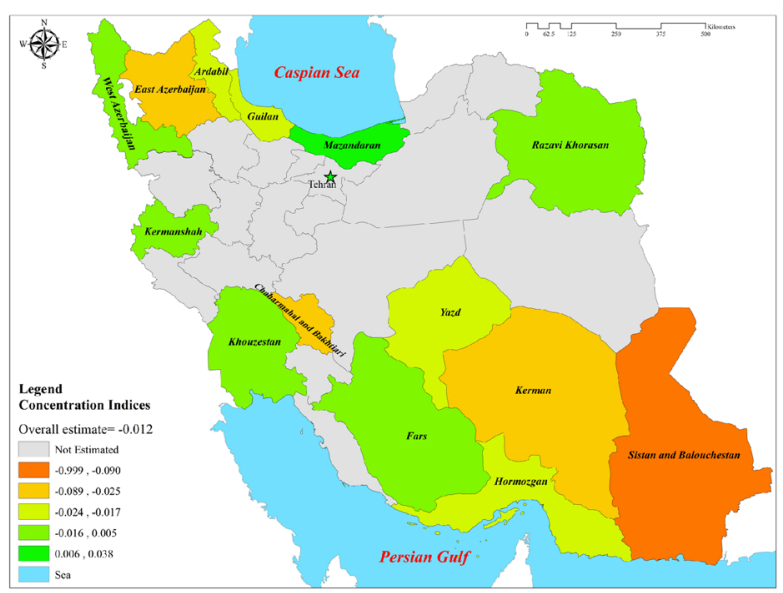

Fig. 1 a Poor mental health prevalence by province of Iran. $\mathbf{b}$ The $C_{k}$ of poor mental health by province of Iran 
Table 2 The E for mental health disorders $(n=130,078)$

\begin{tabular}{lll}
\hline & $\mathrm{Cl}$ & $95 \%$ Confidence Interval \\
\hline Overall estimate & -0.012 & $-0.015,-0.009$ \\
Gender & & \\
Female & -0.002 & $-0.007,0.0025$ \\
Male & -0.009 & $-0.013,-0.006$ \\
Province & & \\
Fars (FA) & -0.003 & $-0.011,0.003$ \\
Kermanshah (KSH) & -0.004 & $-0.012,0.003$ \\
Guilan (GU) & -0.017 & $-0.029,-0.004$ \\
East Azerbaijan (EA) & -0.025 & $-0.035,-0.016$ \\
Mazandaran (MA) & 0.038 & $0.026,0.050$ \\
Sistan and Baluchestan (SB) & -0.090 & $-0.107,-0.074$ \\
Yazd (YA) & -0.020 & $-0.031,-0.009$ \\
Kerman (KE) & -0.028 & $-0.041,-0.016$ \\
Khuzestan (KH) & -0.003 & $-0.009,-0.002$ \\
Chaharmahal and Bakhtiari (CB) & -0.045 & $-0.058,-0.029$ \\
Hormozgan (HO) & -0.018 & $-0.029,-0.006$ \\
West Azerbaijan (WA) & -0.004 & $-0.019,0.010$ \\
Ardabil (AR) & -0.020 & $-0.031,-0.010$ \\
Razavi Khorasan (RK) & 0.005 & $-0.006,0.015$ \\
\hline
\end{tabular}

s of poor mental health of predictors such as, age groups, BMI and marital status, SES and province were varying between females and males. The contribution of SES to poor mental health inequality for female was negative $(-12.11 \%)$, while for the male was positive (17.78\%). The contribution of province for both of the gender was negative $(-138.4 \%$ for female vs. $-5.37 \%$ for male). The SES inequality in poor mental health for female and male are mainly explained by age (185.90\%), and SES (17.78\%), respectively.

\section{Discussion}

The overall prevalence of poor mental health among Iranian adult was $6.2 \%$. This is slightly lower than the result of previous studies conducted on general population in Iran $[4,17]$. The observed inconsistency might be related to the different scale or approaches employed for mental health measurements. Our findings highlighted a substantial gender, and provincial heterogeneities in poor mental health distribution. The largest prevalence of poor mental health $(11.7 \%)$ was observed in the cohort site of Sistan and Balouchestan province. This may be explained by a higher frequency of illicit drug use [18] and higher unemployment rate in this province [19]. Noorbala et al. [20] showed a decreased prevalence of mental disorders from $24.6 \%$ (1999) to $15.1 \%$ (2015) in Sistan and Balouchestan province [20]. They also found a higher prevalence in females (17.2\%) as compared to males (13\%). Consistent with literature, the prevalence of mental disorders in was more found to be more common in females and in older age group adults [20-23]. There was not a substantial difference in the poor mental health prevalence among 14 cohort sites.

Except for the Mazandaran site, the E for all sites had negative sign, suggesting a higher concentration of poor mental health in socioeconomically disadvantaged people. This is in line with the previous reports around the world [24-26]. However, the different methods employed for inequality measurement in various studies made the comparison of the concentration indices difficult.

The geographical inequalities in mental health might be explained by cultural differences across different regions of Iran. The geographical inequalities in health outcomes in Iran might be due to differences in unemployment rates, SES, and literacy levels for across different provinces [27]. Although, study by Movahedi et al. (2008) [28] demonstrated a decrease in the geographic inequality in some health indicators, the authors concluded that cross country differences in health remains an important public health problem in Iran.

The findings of this study demonstrated a more concentration of poor mental health among individuals with lower SES. Decomposing analysis demonstrated gender as the main contributor of observed inequality in the poor mental health prevalence. This is in line with the other inequality studies $[29,30]$ that suggested gender as a possible contributor to socioeconomic inequality in mental health. The contribution to $\mathrm{E}$ also showed that both sociodemographic (i.e. age, BMI, marital status, and SES) and geographical predictors (i.e. province) are varying between females and males. In a study by la Torre J et al. (2016) in Spain, mental health was mainly associated with SES among females [23]. Although, gender gaps in health and health-related factors is globally declining [31], it still exists in both developed and developing countries [32]. Females generally experience higher health-related outcomes including mental disorders, and healthcare services utilization [33]. SES of females are generally lower than males (see, for example, a positive value of the $C$ for male in Table 3 ). The combination of poor mental health and lower SES of females as compared to males led to the significant contribution of gender factor to socioeconomic inequality in poor mental health in Iran. Demographic factors such as age and marital status also play an important role in the mental health inequalities in current study. Similar studies conducted in high- and middle-income countries have reported the same results [26, 34]. A study conducted by Morasae et al. (2012) in Tehran, demonstrated a contribution of $13.1 \%$ for age to socioeconomic inequality in mental health in Tehran, Iran [26]. In contrast with a 
Table 3 Decomposition of E of poor mental health $(n=130,078)$

\begin{tabular}{|c|c|c|c|c|}
\hline & Coefficient & Concentration index & Contribution & Contribut \\
\hline \multicolumn{5}{|l|}{ Age groups } \\
\hline $35-40$ & Ref. & - & - & - \\
\hline $40-45$ & .0894003 & 0.0524 & 0.0001 & -1.2071 \\
\hline $45-50$ & .2150607 & 0.030 & 0.0002 & -1.6621 \\
\hline $50-55$ & .3051117 & -0.0048 & -0.0000 & 0.3805 \\
\hline $55-60$ & .3049626 & -0.0577 & -0.0005 & 4.5390 \\
\hline $60-65$ & .2760597 & -0.0788 & -0.0007 & 5.6091 \\
\hline 65 and older & .308196 & -0.0635 & -0.0006 & 5.0436 \\
\hline \multicolumn{5}{|l|}{ Gender } \\
\hline Male & -.43360 & 0.1783 & -0.0024 & 19.9270 \\
\hline Female & Ref. & - & - & - \\
\hline \multicolumn{5}{|l|}{ Marital status } \\
\hline Single & Ref. & & & \\
\hline Married & -0.0611 & 0.0933 & -0.0002 & 1.4656 \\
\hline Divorced & 0.0217 & -0.0779 & -0.0001 & 0.4353 \\
\hline Widowed & 0.0879 & -0.005 & -0.0000 & 0.1132 \\
\hline Other & -0.0986 & -0.0007 & 0.0000 & -0.0178 \\
\hline
\end{tabular}

Water-pipe use

No

Yes

Alcohol Use

No

Yes

Drug use

No

yes

\section{Smoking status}

Non-smoker

Ex-smoker

Smoker

BMI

Underweight

Normal

Overweight

Obese

Physical activity (Daily METs)

Inactive (24-36.5)

Middle (36.6-44.9)

Active $(\geq 45)$

Socioeconomic status

1st SES quintile (Poorest)

2nd SES quintile

3rd SES quintile

4th SES quintile
$-0.0986$

Ref.

0.0623

0.0712

0.0001

$-1.1424$

Ref.

$-0.0487$

0.0677

$-0.0001$

0.8492

Ref.

0.1552

$-0.0094$

$-0.0000$

$-0.1247$

Ref.

0.21844

0.12433

$-0.0006$

0.0049

$-0.0225$

0.01042

Ref.

0.02785

0.0784

0.0225

0.04223

Ref.

$-0.1956$

0.0703

$-0.3385$

$-0.1068$

Ref.

0.03825

0.05155

$-0.3191$

0.0012

0.3197

19.927

1.9963

$-1.1424$

0.8492

0.3762

0.3762

0.0336

$-0.1583$

$-0.7472$

0.0605

$-0.5632$

$-0.2445$

$-5.7784$

$-0.0004$

3.5431

0.0011

$-9.3215$

10.0531

$-0.0004$

3.1463

0.0000

$-0.0154$

0.00051

0.0000

$-0.0421$ 
Table 3 Decomposition of $\mathrm{E}$ of poor mental health $(n=130,078)$ (Continued)

\begin{tabular}{|c|c|c|c|c|c|}
\hline & Coefficient & Concentration index & Contribution & Contribution\% & Summed \\
\hline 5th SES quintile (Richest) & -0.04223 & 0.6397 & -0.0008 & 6.9643 & \\
\hline Region of cohort (province) & & & & & -11.0293 \\
\hline Fars (FA) & Ref. & & & & \\
\hline Kermanshah (KSH) & -0.3517 & -0.0209 & 0.0002 & -1.8938 & \\
\hline Guilan (GU) & 0.19355 & -0.0483 & -0.0003 & 2.4108 & \\
\hline East Azerbaijan (EA) & 0.1363 & -0.0057 & -0.0000 & 0.1992 & \\
\hline Mazandaran (MA) & 0.3011 & 0.0461 & 0.0004 & -3.5757 & \\
\hline Sistan and Balouchestan (SB) & 0.3056 & 0.0082 & 0.0001 & -0.6435 & \\
\hline Yazd (YA) & 0.0654 & 0.0536 & 0.0001 & -0.9046 & \\
\hline Kerman (KE) & 0.1688 & 0.0847 & 0.0004 & -3.6822 & \\
\hline Khuzestan (KH) & -0.6571 & -0.0497 & 0.0010 & -8.4243 & \\
\hline Chaharmahal and Bakhtiari (CB) & 0.0956 & 0.0921 & 0.0003 & -2.2701 & \\
\hline Hormozgan (HO) & -0.2641 & -0.0056 & 0.0000 & -0.3815 & \\
\hline West Azerbaijan (WA) & -0.1006 & -0.0183 & 0.0001 & -0.4738 & \\
\hline Ardabil (AR) & -0.1215 & 0.0551 & -0.0002 & 1.7239 & \\
\hline Razavi Khorasan (RK) & -0.4975 & 0.0537 & -0.0008 & 6.8863 & \\
\hline Total & & & & & 27.083 \\
\hline Residual & & & & & 72.917 \\
\hline The $\mathrm{E}$ & & & -0.012 & & 100.0 \\
\hline
\end{tabular}

Physical activity (Daily METs): A MET is equal to resting metabolic rate, the amount of oxygen consumed at rest that is about $3.5 \mathrm{ml} 02 / \mathrm{kg} / \mathrm{min}$

Ref. indicated reference group in the regression estimation

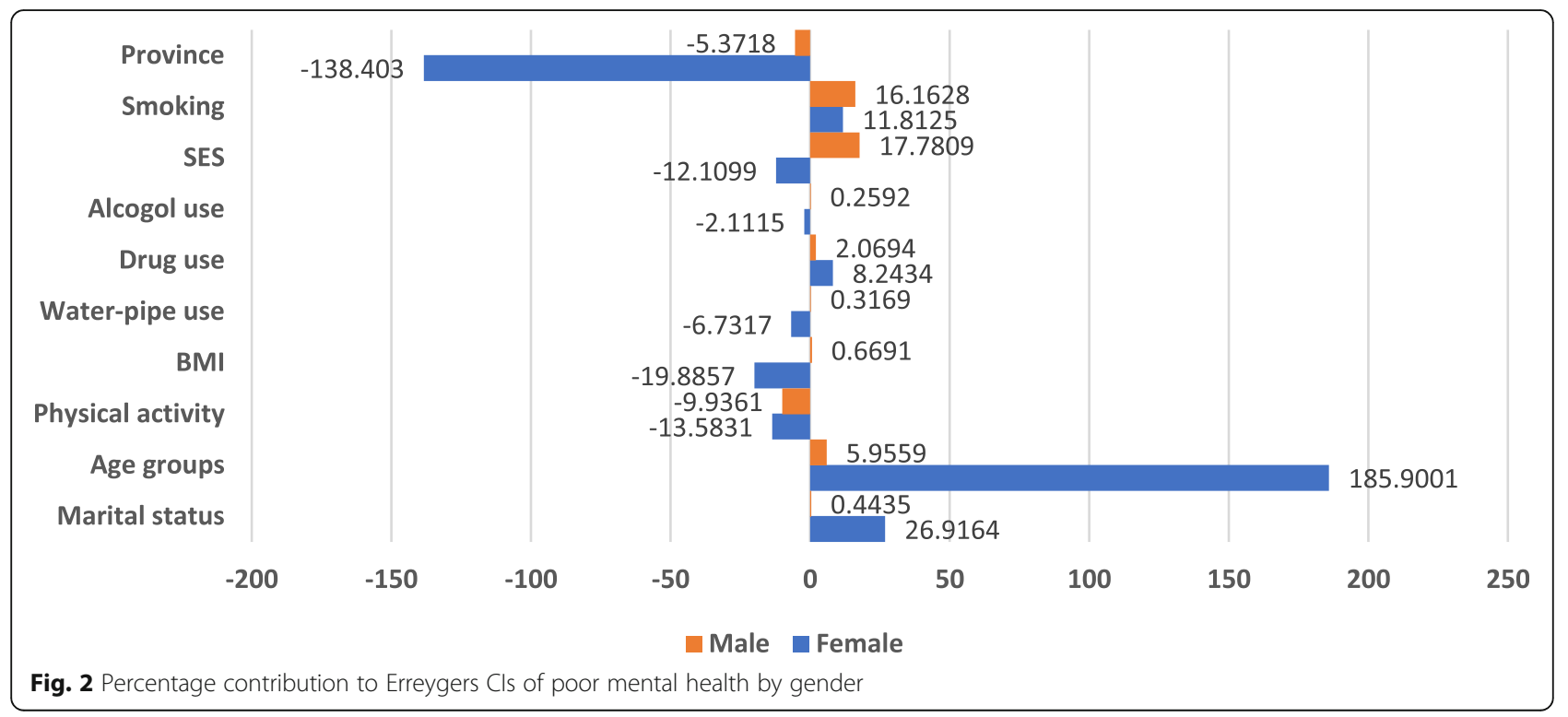




\section{Appendix}

Table 4 The characteristics of the PERSIAN cohort sites included in the study

\begin{tabular}{|c|c|c|c|c|c|c|}
\hline & Province & Population & Cohort site & Population & Cohort population & Main Ethnicities \\
\hline 1 & Ardabil & $1,270,420$ & Ardabil & 529,374 & 8192 & Azeri Turk \\
\hline 2 & Chaharmahal and Bakhtiari & 947,763 & Sharekord & 93,104 & 6664 & Lor \\
\hline 3 & East Azerbaijan & $3,909,652$ & Khameneh & 3056 & 14,978 & Azari Turk \\
\hline \multirow[t]{3}{*}{4} & \multirow[t]{3}{*}{ Fars } & \multirow[t]{3}{*}{$4,851,274$} & Kavar & 31,711 & 2244 & Fars (Persian), Turk \\
\hline & & & Kharameh & 18,477 & 10,662 & Fars (Persian), Arab \\
\hline & & & Fasa & 110,825 & 10,113 & Fars (Persian), Arab and Turk \\
\hline 5 & Guilan & $2,530,696$ & Some'e Sara & 58,658 & 10,511 & Gilaki \\
\hline 6 & Hormozgan & $1,776,415$ & Bandare Kong & 19,213 & 3570 & Arab \\
\hline 7 & Kerman & $3.164,718$ & Rafsanjan & 161,909 & 9982 & Fars (Persian) \\
\hline 8 & Kermanshah & $1,952,434$ & Ravansar & 47,657 & 10,077 & Kurd \\
\hline 9 & Khouzestan & $4,710,506$ & Hoveizeh & 19,481 & 9156 & Arab \\
\hline 10 & Mazandaran & $3,283,582$ & Sari & 309,820 & 10,253 & Tabari \\
\hline \multirow[t]{2}{*}{11} & \multirow[t]{2}{*}{ Razavi Khorasan } & \multirow[t]{2}{*}{$6,434,501$} & Mashhad & $3,001,184$ & 2189 & Fars (Persian) \\
\hline & & & Sabzevar & 243,700 & 784 & Fars (Persian) \\
\hline 12 & Sistan and Balouchestan & $2,775,014$ & Zahedan & 587,730 & 8318 & Balouch \\
\hline 13 & West Azerbaijan & $3,265,219$ & Ghoushchi & 2787 & 3662 & Azeri Turk \\
\hline 14 & Yazd & $1,138,533$ & Shahedieh, Yazd & 18,309 & 9901 & Fars (Persian) \\
\hline
\end{tabular}

References: 1- Persian cohort sites, available from: http://persiancohort.com/cohortsites/, access: April 21, 2019. 2- Iran statistics center, available from: https:// www.amar.org.ir, access: April 21, 2019

study by Amroussia et al. [24], marital status had a small contribution to socioeconomic inequalities in poor mental health in Iran. Married people (compared to single, divorced and widowed) were found to have more contribution to socioeconomic inequality in poor mental health. This finding may be related to financial limitation that puts strains on marital relationship among couple. People from low socioeconomic groups usually experience more poor marital relationship, intimate partner violence, financial stress and pressure than those in high socioeconomic groups [35, 36].

There are a number of limitations need to be considered when interpreting the study results. First, the selfreported nature of drug use for mental health disorders might lead to recall bias. Second, because of the crosssectional nature of the data, it was not possible to establish a causal correlation between explanatory variables and poor mental health outcome. Third, the estimated prevalence and the E may not be a representative sample of entire of Iran as data was not collected from some provinces in Iran.

\section{Conclusion}

The findings of the study showed that poor mental health is nearly equitable distributed among Iranian adults, but with important variations by gender, SES, and geography. These results suggested that interventional programs in Iran should focus on should focus more on socioeconomically disadvantaged people as a whole, with particular attention to the needs of women and those living in more socially disadvantaged regions.

\section{Abbreviations}

PERSIAN: Prospective epidemiological research in IrAN; SES: Socioeconomic status; BMI: Body mass index; C: Concentration index; E: Erreygers

concentration index

\section{Acknowledgments}

We would like to thank Prof. Reza Malekzadeh, the Deputy of Research and Technology at the Ministry of Health and Medical Education of Iran and Director of the PERSIAN cohort, as well as Dr. Hossein Poustchi, the Executive Director of the PERSIAN cohort, for all their support during the design and implementation of this study.

\section{Authors' contributions}

F N, Y P, B KM, S R, AKK, SS, MS, AZ, MM, BH, S E, Mkh, S Sh, AHM, ZK, AN, $M N$, ShSB, AF, BCh, HH, PMand MH contributed in the PERSIAN cohort design, data collection and had critical feedback on manuscript. YS, ZJSh, ShR, and MSajjadipour assisted in the prepare data for analysis and data analysis, writing and critically reviewing multiple manuscript drafts. All authors contributed to manuscript revision, read and approved the submitted version.

Funding

We did not receive any funds for publication of this study.

Availability of data and materials

The datasets analyzed during the current study are available from the corresponding author on reasonable request. 


\section{Ethics approval and consent to participate}

Data were collected after obtaining written informed consent from all of the participants. While each cohort center received the ethical approval from local universities, for the purpose of this study and pooling all PERSIAN site data, the ethics committee of Kermanshah University of Medical Sciences approved the study (IR.KUMS.REC.1397.866).

\section{Consent for publication}

Not applicable.

\section{Competing interests}

There is no conflict of interest to be declared.

\section{Author details}

${ }^{1}$ Research Center for Environmental Determinants of Health, Health Institute, Kermanshah University of Medical Sciences, Kermanshah, Iran. ${ }^{2}$ Nutritional Sciences Department, School of Public Health, Kermanshah University of Medical Sciences, Kermanshah, Iran. ${ }^{3}$ Social Development and Health Promotion Research Center, Health Institute, Kermanshah University of Medical Sciences, Kermanshah, Iran. ${ }^{4}$ Social Determinants of Health Research Center, University of Social Welfare and Rehabilitation Sciences, Tehran, Iran. ${ }^{5}$ South Tehran Health Center, Tehran University of Medical Sciences, Tehran, Iran. ${ }^{6}$ Pharmaceutical Research Center, Pharmaceutical Research Institute, Mashhad University of Medical Sciences, Mashhad, Iran. ${ }^{7}$ Cellular and molecular research center, school of medicine, Sabzevar university of medical sciences, Sabzevar, Iran. ${ }^{8}$ Health Promotion Research Center, Zahedan University of Medical Sciences, Zahedan, Iran. ${ }^{9}$ Industrial Diseases Research Center, Shahid Sadoughi University of Medical Sciences, Yazd, Iran. ${ }^{10}$ Diabetes Research Center, Mazandaran University of Medical Sciences, Sari, Iran. ${ }^{11}$ Molecular Medicine Research Center, Hormozgan University of Medical Sciences, Bandar Abbas, Iran. ${ }^{2}$ Gastrointestinal and liver disease research center, Guilan University of medical sciences, Rasht, Iran.

${ }^{13}$ Gastroenterohepatology Research Center, Shiraz university of medical sciences, Shiraz, Iran. ${ }^{14}$ Research Center of psychiatry and behavioral sciences, Tabriz University of Medical sciences, Tabriz, Iran. ${ }^{15}$ Department of Biostatistics and Epidemiology, school of public health, Ahvaz jundishapur university of medical sciences, Ahvaz, Iran. ${ }^{16}$ Modeling in Health Research Center, Shahrekord University of Medical Sciences, Shahrekord, Iran. ${ }^{17}$ Digestive Disease Research Center, Ardabil University of Medical Sciences, Ardabil, Iran. ${ }^{18} \mathrm{~S}$ chool of Health Administration, Faculty of Health, Dalhousie University, Halifax, Canada. ${ }^{19}$ Social Development and Health Promotion Research Center, Health Institute, Kermanshah University of Medical Sciences, Kermanshah, Iran.

Received: 9 September 2019 Accepted: 12 April 2020

Published online: 13 May 2020

\section{References}

1. Friedli L. Mental health, resilience and inequalities. Denmark: WHO Regional Office for Europe. 2009. https://apps.who.int/iris/handle/10665/107925. Accessed 20 Apr 2020.

2. Steel Z, Marnane C, Iranpour C, Chey T, Jackson JW, Patel V, Silove D. The global prevalence of common mental disorders: a systematic review and meta-analysis 1980-2013. Int J Epidemiol. 2014;43(2):476-93.

3. James SL, Abate D, Abate KH, Abay SM, Abbafati C, Abbasi N, Abbastabar H, Abd-Allah F, Abdela J, Abdelalim A, et al. Global, regional, and national incidence, prevalence, and years lived with disability for 354 diseases and injuries for 195 countries and territories, 1990-2017: a systematic analysis for the global burden of disease study 2017. Lancet. 2018;392(10159):1789-858.

4. Noorbala AA, Yazdi SAB, Faghihzadeh S, Kamali K, Faghihzadeh E, Hajebi A, Akhondzadeh S, Esalatmanesh S, Yazdi HB, Abbasinejad M. Trends of mental health status in Iranian population aged 15 and above between 1999 and 2015. Arch Iran Med. 2017;20(11):S2.

5. Lund C, Breen A, Flisher AJ, Kakuma R, Corrigall J, Joska JA, Swartz L, Patel V. Poverty and common mental disorders in low and middle income countries: a systematic review. Soc Sci Med. 2010;71(3):517-28.

6. Reiss F. Socioeconomic inequalities and mental health problems in children and adolescents: a systematic review. Soc Sci Med. 2013;90:24-31.

7. Patel V LC, Hatherill S, Plagerson S, Corrigall J, Funk M, Flisher AJ: Mental disorders: equity and social determinants. In Equity, Social Determinants and Public Health Programs. 2010:115-134.
8. Rogers A PD: Mental health and inequality New York: Palgrave Macmillan. 2003.

9. Allen J, Balfour R, Bell R, Marmot M. Social determinants of mental health. Int Rev Psychiatry. 2014;26(4):392-407.

10. Poustchi H, Eghtesad S, Kamangar F, Etemadi A, Keshtkar A-A, Hekmatdoost A, Mohammadi Z, Mahmoudi Z, Shayanrad A, Roozafzai F. Prospective epidemiological research studies in Iran (the PERSIAN cohort study): rationale, objectives, and design. Am J Epidemiol. 2017;187(4):647-55.

11. Eghtesad S, Mohammadi Z, Shayanrad A, Faramarzi E, Joukar F, Hamzeh B, Farjam M, Sakhvidi MJZ, Miri-Monjar M, Moosazadeh M. The PERSIAN cohort: providing the evidence needed for healthcare reform. Arch Iran Med. 2017;20(11):691.

12. Wagstaff A, Paci P, Van Doorslaer E. On the measurement of inequalities in health. Soc Sci Med. 1991;33(5):545-57.

13. Kakwani N. On a class of poverty measures. Econometrica: J Econometric Soc. 1980;48(2):437-46.

14. Erreygers G. Correcting the concentration index. J Health Econ. 2009;28(2):504-15.

15. StataCorp L. Stata statistical software, version 11. StataCorp College Station (TX): StataCorp LP; 2009.

16. O'Donnell O, O'Neill S, Van Ourti T, Walsh B. Conindex: estimation of concentration indices. Stata J. 2016;16(1):112.

17. Hassanzadeh J, Asadi-Lari M, Ghaem H, Kassani A, Niazi M, Menati R. The Association of Poor Mental Health Status and Sociocultural Factors in men: a population-based study in Tehran, Iran. Am J Mens Health. 2018;12(1):96-103.

18. Amin-Esmaeili M, Rahimi-Movaghar A, Sharifi V, Hajebi A, Radgoodarzi R, Mojtabai R, Hefazi M, Motevalian A. Epidemiology of illicit drug use disorders in Iran: prevalence, correlates, comorbidity and service utilization results from the Iranian mental health survey. Addiction. 2016;111(10):1836-47.

19. StatisticalCenter. A Selection of Labor Force Survey Results-Summer 1397 ( 21 Mar. 2018-20 Mar. 2019), Statistical Center of Iran. Tehran: Statistical Center of Iran; 2018.

20. Noorbala AA, Bagheri Yazdi SA, Faghihzadeh S, Kamali K, Faghihzadeh E, Hajebi A, Akhondzadeh S, Shakiba M, Sargazi F, Shahriari S. A survey on mental health status of adult population aged 15 and above in the Province of Sistan and Bluchestan, Iran. Arch Iran Med. 2017;20(11 Suppl. 1): S107-s110.

21. Noorbala AA, Bagheri Yazdi SA, Faghihzadeh S, Kamali K, Faghihzadeh E, Hajebi A, Akhondzadeh S, Ghazizadeh Hashemi F, Okhravi N. A survey on mental health status of adult population aged 15 and above in the Province of Razavi Khorasan, Iran. Arch Iran Med. 2017;20(11 Suppl. 1):S99-s102.

22. Noorbala AA, Bagheri Yazdi SA, Faghihzadeh S, Kamali K, Faghihzadeh E, Hajebi A, Akhondzadeh S, Shakiba A, Hashem Zehi MR. A Survey on mental health status of adult population aged 15 and above in the Province of Mazandaran, Iran. Arch Iran Med. 2017;20(11 Suppl. 1):S83-s86.

23. Arias-de la Torre J, Artazcoz L, Molina AJ, Fernandez-Villa T, Martin V. Inequalities in mental health in the working population of Spain: a national health survey-based study. Gac Sanit. 2016;30(5):339-44.

24. Amroussia N, Gustafsson PE, Mosquera PA. Explaining mental health inequalities in northern Sweden: a decomposition analysis. Glob Health Action. 2017;10(1):1305814.

25. Mangalore R, Knapp M, Jenkins R. Income-related inequality in mental health in Britain: the concentration index approach. Psychol Med. 2007; 37(7):1037-45.

26. Morasae EK, Forouzan AS, Majdzadeh R, Asadi-Lari M, Noorbala AA, Hosseinpoor AR. Understanding determinants of socioeconomic inequality in mental health in Iran's capital, Tehran: a concentration index decomposition approach. Int J Equity Health. 2012;11:18.

27. Rostami M, Karamouzian M, Khosravi A, Rezaeian S. Gender and geographical inequalities in fatal drug overdose in Iran: a provincelevel study in 2006 and 2011. Spat Spatio-Temporal Epidemiol. 2018;25: $19-24$.

28. Movahedi M, Hajarizadeh B, Rahimi A, Arshinchi M, Amirhosseini K, Haghdoost AA. Trends and geographical inequalities of the main health indicators for rural Iran. Health Policy Plan. 2009;24(3):229-37.

29. Klanscek HJ, Ziberna J, Korosec A, Zurc J, Albreht T. Mental health inequalities in Slovenian 15-year-old adolescents explained by personal social position and family socioeconomic status. Int J Equity Health. 2014;13:26.

30. Thomson RM, Niedzwiedz CL, Katikireddi SV. Trends in gender and socioeconomic inequalities in mental health following the great recession and subsequent austerity policies: a repeat cross-sectional analysis of the health surveys for England. BMJ Open. 2018;8(8):e022924. 
31. Dorius SF, Firebaugh G. Trends in global gender inequality (forthcoming, social forces). Soc Forces. 2010;88(5):1941-68.

32. Hassanzadeh J, Moradi N, Esmailnasab N, Rezaeian S, Bagheri P, Armanmehr $V$. The correlation between gender inequalities and their health related factors in world countries: a global cross-sectional study. J Epidemiol Res Int. 2014;2014:8.

33. Brand E, Rodriguez-Monguio R, Volber R. Gender differences in mental health and substance use disorders and related healthcare services utilization. Am J Addict. 2019;28(1):9-15.

34. Wildman J. Income related inequalities in mental health in Great Britain: analysing the causes of health inequality over time. J Health Econ. 2003; 22(2):295-312.

35. Assari S, Jeremiah RD. Intimate partner violence may be one mechanism by which male partner socioeconomic status and substance use affect female partner health. Front Psychiatry. 2018;9:160.

36. Choi G-Y, Byoun S-J. Domestic violence against migrant women in South Korea: addressing the needs of a uniquely situated victim population in domestic violence policy. Int Soc Work. 2014;57(6):645-60.

\section{Publisher's Note}

Springer Nature remains neutral with regard to jurisdictional claims in published maps and institutional affiliations.

Ready to submit your research? Choose BMC and benefit from:

- fast, convenient online submission

- thorough peer review by experienced researchers in your field

- rapid publication on acceptance

- support for research data, including large and complex data types

- gold Open Access which fosters wider collaboration and increased citations

- maximum visibility for your research: over $100 \mathrm{M}$ website views per year

At $\mathrm{BMC}$, research is always in progress.

Learn more biomedcentral.com/submissions 